\title{
Pathways to school completion for young mothers: Are we winning the fight?
}

\author{
N Pillay, MSocSci \\ School of Public Health, University of the Witwatersrand, Johannesburg, South Africa
}

Corresponding author: N Pillay (nirvana@sarraounia.org)

\begin{abstract}
Background. Policy initiatives in South Africa are directed at promoting the educational and developmental outcomes of girls and young women (age 15 - 24 years). These include decreasing the incidence of HIV infection, teenage pregnancy and gender-based violence, and increasing school attendance and economic empowerment. This article explores the contexts of pregnancy, motherhood and schooling in a sample of young mothers in an urban area in Johannesburg, South Africa.

Methods. This ethnographic study, based in a poor urban area in Johannesburg, South Africa, recruited 30 young mothers aged 18 - 20 years with whom open-ended interviews were conducted. Each mother was contacted 3 months after the first interview, and again 3 months later. In addition to the first round of 30 interviews, 9 young mothers were interviewed in the second round, and 6 young mothers in a third round. A total of 45 interviews were conducted.

Results. The findings illustrate how young mothers mediate constraints and challenges to continue and complete their schooling when confronted with a mistimed and unintended pregnancy. A combination of factors converge to facilitate or impede school continuation and completion. Key barriers include school policy and discrimination against pregnant learners, limited options for childcare, and high levels of poverty and unemployment that strain existing scarce family resources.

Conclusions. The pathway to school completion is complex and non-linear. Three particular interventions that support school attendance and completion for young mothers have value: the child support grant, the availability of crèches in the community, and a school policy that upholds the principle of inclusivity for pregnant learners and young mothers.
\end{abstract}

S Afr J Child Health 2018;12(2 Suppl 1):S15-S18. DOI:10.7196/SAJCH.2018.v12i2.1530

The National Development Plan (NDP) 2030, South Africa's blueprint for socioeconomic growth and achieving the country's Sustainable Development Goals (SDGs), identifies education as one of 14 priority goals. ${ }^{[1]}$ In elaborating on this aim, current policy aims to promote the educational and developmental outcomes of girls and young women by decreasing the incidence HIV, teenage pregnancy and gender-based violence, and increasing school attendance and economic empowerment. ${ }^{[2,3]}$ The present article explores pregnancy, motherhood and schooling in a sample of young mothers (aged 18 - 20 years) in a resource-poor urban area in Johannesburg, South Africa. Understandings of the barriers to school continuation, completion and further education are contextualised, and attention is given to the factors that facilitate school completion for young mothers.

There is a paucity of recent age-disaggregated data on teenage pregnancy. Census 2001 reported that $1 \%$ of girls aged 14 years had given birth to at least 1 child; increasing to $2.8 \%$ at age 15 ; $6.5 \%$ at $16 ; 13.1 \%$ at $17 ; 21.9 \%$ at 18 ; and $30.5 \%$ at age $19 .{ }^{[4]}$ Birth rates increase significantly among older teenagers, many of whom are in their final year of school or have just started post-secondary education. ${ }^{[5-7]}$ The focus of this study was therefore on mothers aged 18 to 20 .

The reasons for and consequences of teenage pregnancy, particularly as it relates to educational outcomes, are well understood. ${ }^{[8-10]}$ Barriers to school completion for young mothers are exacerbated by higher levels of grade repetition and dropping out, and lower levels of school completion. ${ }^{[11,12]}$ The dominant discourse around early motherhood is pejorative, with messages of shame and blame and experiences of discrimination. ${ }^{[13-15]}$ Nevertheless, pregnancy and schooling co-exist in South Africa more than in other countries with high teenage pregnancy rates. ${ }^{[16,17]}$ Progressive policy and legislation such as the South African
Schools Act No. 84 of $1996^{[18]}$ endorses the rights of pregnant learners to continue with formal education.

Madhavan and Thomas ${ }^{[16]}$ argue that the main factors that determine whether young mothers complete their schooling are availability of financial support and childcare. These factors include childcare facilities, social welfare and removal of the stigma associated with early motherhood. ${ }^{[9,16]}$ Less clear is the sequencing of events and causal relationships between poor performance, pregnancy, school withdrawal, low further education enrolment and limited capacity to access available employment opportunities. ${ }^{[17]}$ The present article aims to shed light on the sequence of events from conception to school attendance and completion in a sample of young mothers in Johannesburg, South Africa.

\section{Methods}

This ethnographic study, based in a resource-poor urban area in Johannesburg, was conducted as a doctoral research project. Ethics clearance was received from the University of the Witwatersrand Human Research Ethics Committee (Medical; M160535). Permission for the study was granted by the Johannesburg Health District Research Committee and is registered on the South African National Health Research Database.

Between September 2016 and September 2017, 30 young mothers (18 - 20 years), recruited through a local community health centre, participated in open-ended interviews of approximately $30-60$ minutes. In the course of the year, contact with the participants was maintained via WhatsApp and SMS, with the aim of interviewing them 2 - 3 times. In total, 45 interviews were conducted, including an initial interview with 30 young mothers, a second interview with 9 , and a third interview with 6 (total interviews 45). Respondents received ZAR40 at each interview to contribute to cellphone costs in order to keep in contact with the researcher. 
An in-depth, open-ended interview guide was used to elicit narratives to explore three main areas of inquiry: pregnancy and birth; education and continuing education; and support networks. The approach drew on the meanings that young mothers gave to their reality, emphasising their direct experience, as is common in ethnographic research. ${ }^{[19]}$ The length and pace of each interview was determined by the young mother, and the ease with which she was able to participate in the interview while caring for her baby. Interviews were conducted in English; the mothers were offered a translator but in all instances refused.

Data collection and data analysis were conducted simultaneously and iteratively. All interviews were transcribed verbatim. Thematic analysis was conducted using MaxQDA, through line-by-line coding to ensure a comprehensive review of the data, and then to identify primary themes and subthemes. Excel was used for simple statistical analysis to show trends in the thematic data.

\section{Results}

Ethnographic fieldwork does not aim to quantify data, and this study does not claim to be representative nationally or provincially. However, the data provide some opportunities for simple quantitative analysis. The results show trends in the data, complemented by young mothers' narratives of why and how school completion was facilitated and challenged. The quantitative results are based on data from the first interview, and information gained during subsequent interviews was not included. The term 'young mother' instead of 'teenage mother' is used in the results as an inclusive term for all mothers between 18 and 20 years of age. The age of the mother in parentheses is the age at first interview. Pseudonyms have been used for all mothers quoted in the article to ensure anonymity. In the sample, 18 mothers were in a relationship with the father of the baby at the time of first interview, and 19 mothers were receiving the state child support grant. Table 1 summarises the findings from this study in terms of school completion, school withdrawal and matriculation.

The results indicate that the pathways to school completion for mothers who were in school at the time of pregnancy are complex, and that numerous factors influence the trajectory to school completion or dropping out.

\section{Remaining at school}

Various factors converge to facilitate young mothers remaining at school during pregnancy and after the birth. Reactions to their pregnancies ranged across schools from support for the young mother, not acknowledging the pregnancy and simply treating her like any other learner, to attempts to dismiss her from school because of the pregnancy. Support included advice, encouragement and kindness from teachers. Andiswa (18) related the following act of kindness from teachers:

'Sometime if I don't have lunch then they [teacher] will buy me lunch. "How is the baby," asking, and I will say "Ja, he is doing OK." "OK, I will come and see the baby when I've got time," he said.'
At the other end of the spectrum, Sesi (19), who was in her matriculation year in 2015 when she conceived, was asked by the school principal to leave school when her pregnancy was made known. Her mother, Queen, would not accept this, and advocated for Sesi's right to remain at school. When the school principal argued that they did not want to be responsible for the health of pregnant learners, Queen arranged for her sister, Sesi's aunt, to accompany Sesi to school daily for the duration of the pregnancy. Nine out of 13 young mothers who continued their education attended schools in the study setting where pregnancy did not affect their access.

Childcare is critical for young mothers who remain at school. For many mothers, the child support grant enabled them to pay for caregiving. Linda (18), for example, said that she used ZAR300 for crèche for her child, and the remaining amount to buy things for her child. However, some young mothers did not trust crèches, because of the limited number of trained staff to care for large numbers of babies, and they opted instead to find paid caregivers. For example, Kheti (18) usually lived with her sister, but she had no experience with infants. After giving birth, Kheti stayed with and received care from the infant's paternal grandmother for 2 months; the grandmother provided financial and personal support, including paying for a caregiver when Kheti returned to school.

Many participants who remained at school said that they felt under pressure to complete schooling so as not to disappoint their parents and waste their parents' investment in their education. However, despite remaining at school, young mothers achieved different levels of school completion, with only 6 of the 13 mothers in school at the time of conception completing their matriculation year.

\section{Temporarily withdrawing from school}

Young mothers who temporarily withdrew from school, but returned after the birth, cited school policy as the primary reason for the temporary break; this was closely linked with personal shame and embarrassment in attending school while pregnant. On the other hand, some young mothers came to Johannesburg to pursue their education after they had experienced discrimination at schools elsewhere in the country. Dzuvha (20) left Limpopo Province because the school in Venda 'did not want anyone who was pregnant'. Once the baby was born, Dzuvha moved to Johannesburg to join her mother and continue her schooling.

In some instances, young mothers anticipated a negative reaction from school, and dropped out temporarily to avoid possible embarrassment and shame. For example, Boitumelo (18) left school assuming she would be excluded, although she later realised this was unnecessary:

'They [school] were like, why did you not come back [to school], do you attend [school] elsewhere? I was like, no, I have a child. Then they were like, on January we need you here, this school is empty without you, and that gave me the confidence of saying, oh I must go back to school.'

Negotiating a new role as a pregnant learner is onerous, and some young mothers temporarily take a break because they cannot cope

Table 1. Summary of school-related data at pregnancy

\begin{tabular}{llllllll}
\hline & \multicolumn{5}{c}{ Age (years) } \\
\cline { 2 - 6 } Variables & $\mathbf{1 5}$ & $\mathbf{1 6}$ & $\mathbf{1 7}$ & $\mathbf{1 8}$ & $\mathbf{1 9}$ & $\mathbf{2 0}$ & Total \\
\hline School completed & 0 & 0 & 0 & 1 & 3 & 2 & 6 \\
In school & 2 & 2 & 5 & 9 & 4 & 2 & 24 \\
Remained at school during pregnancy and after & 0 & 1 & 5 & 6 & 2 & 0 & 13 \\
Withdrew from school during pregnancy & 2 & 1 & 1 & 3 & 2 & 2 & 11 \\
Returned to school after pregnancy and birth & 1 & 1 & 1 & 2 & 1 & 0 & 6 \\
Did not return to school & 1 & 0 & 0 & 1 & 1 & 2 & 5
\end{tabular}


with caring for their infant and studying. In these instances, the decision was made by the young mother, and school, family and peers had little influence. In other instances, decisions around temporary withdrawal were made by other family members because of their concern for the health and wellbeing of the young mother. Lerato (19) described her grandmother's concern:

'My granny didn't want me to go to school because she thinks that, she thought like, I will get sick at school you know. Because sometimes at school I was getting dizzy, not feeling well and so she told me to stop going to school because she doesn't know what will happen to me...'

Although Lerato was unhappy with this absence, she felt unable to assert herself as she was dependent on her grandmother and felt she had already burdened her by falling pregnant.

\section{Permanent withdrawal from school}

School policy, the inability to manage the dual roles of mother and learner, and insufficient support to care for the baby resulted in permanent withdrawal from school for 5 young mothers. Two of these left school when their schools enforced a non-admission policy for pregnant learners. A school principal (in Eastern Cape) refused Fezeka's (20) admission, and shamed and abused her:

'The principal just called me to the office and say, I must show her my stomach, then I did so then he [actually she] said to me you are pregnant...'

Lindi's (20) school in another poor urban area in Johannesburg also made it clear that pregnant learners were not welcome. Her mother attempted to convince the principal to allow her daughter to continue, but the school administration remained steadfast. Lindi dropped out. Bontle (19) was taught by her mother to take responsibility for her 'mistake'; she was forced to discontinue her schooling as punishment:

'I couldn't go back [to school] because my mother said I should take care of the baby, no one's going to take care of my baby because it is a choice that I made and I wanted to have a baby while I was still schooling.'

Betty (20) was completing Grade 11 when she became pregnant. The school did not ask her to leave, but she did so because she found it difficult to study while pregnant. Pule (18) had three children, and she had left school after her first pregnancy at age 14 because of the combined pressures of poverty, limited support for caregiving, and her subsequent pregnancies.
Further education and employment Opportunities to pursue further education and employment are limited for young mothers who had their babies after school completion. In this study, 6 mothers had completed their schooling when they discovered they were pregnant. In all cases, the pregnancy led to a temporary pause in further education and employment. Two young mothers had passed their matriculation examinations with bachelor passes, which would have gained them university entrance. Ntokozo (19) was accepted into a nursing college and awarded a scholarship, but she was refused admission by the college because of pregnancy. In this instance, opportunity for further study was directly affected by the unintended and mistimed pregnancy. Two mothers had completed their secondary schooling in Zimbabwe, and remained at home with their babies. The remaining 2 mothers combined some level of further education and training, part-time employment, and infant care.

\section{Discussion}

The pathways to school completion are complex and non-linear, as described in the results and summarised in Fig. 1. The qualitative nature of the study allowed in-depth exploration of the factors that support continued schooling, and both permanent and temporary school withdrawal, illustrating how personal experiences and circumstances of everyday life both support and disrupt dominant narratives of early motherhood.
In this study, the permanent drop-out rate $(5 / 24,20.8 \%)$ for young mothers was much lower than the $33 \%$ attributed to teenage pregnancy and childbearing by the National Income Dynamic Study. ${ }^{[20]}$ This finding supports Madhavan's and Thomas's ${ }^{[16]}$ claim that teenage pregnancy and schooling in South Africa are not mutually exclusive. The results illustrate the importance of school policy in facilitating or impeding access to school for young mothers. More than 20 years after the Schools Act No. 84 of $1996,{ }^{[18]}$ the policies of individual schools towards learner pregnancy continue to impede school completion for some young mothers, contravening both the law and the Constitution. ${ }^{[13,14,21]}$ While some young mothers who had been attending school in other provinces and elsewhere in Johannesburg were excluded when pregnant, this was not true for all young mothers in the study setting, thus removing a significant obstacle to school completion in this community. However, young mothers may 'choose' to withdraw from school on a temporary basis to avoid shame, highlighting the complex interplay between the agency of the young mother to avoid embarrassment, and the power of the school in influencing her education decisions.

Women's agency to challenge the dominant pejorative discourse around young mothers, advocacy for their rights as pregnant learners, and care and support in complex circumstances, significantly facilitated school completion. The woman who challenged school policy exercised

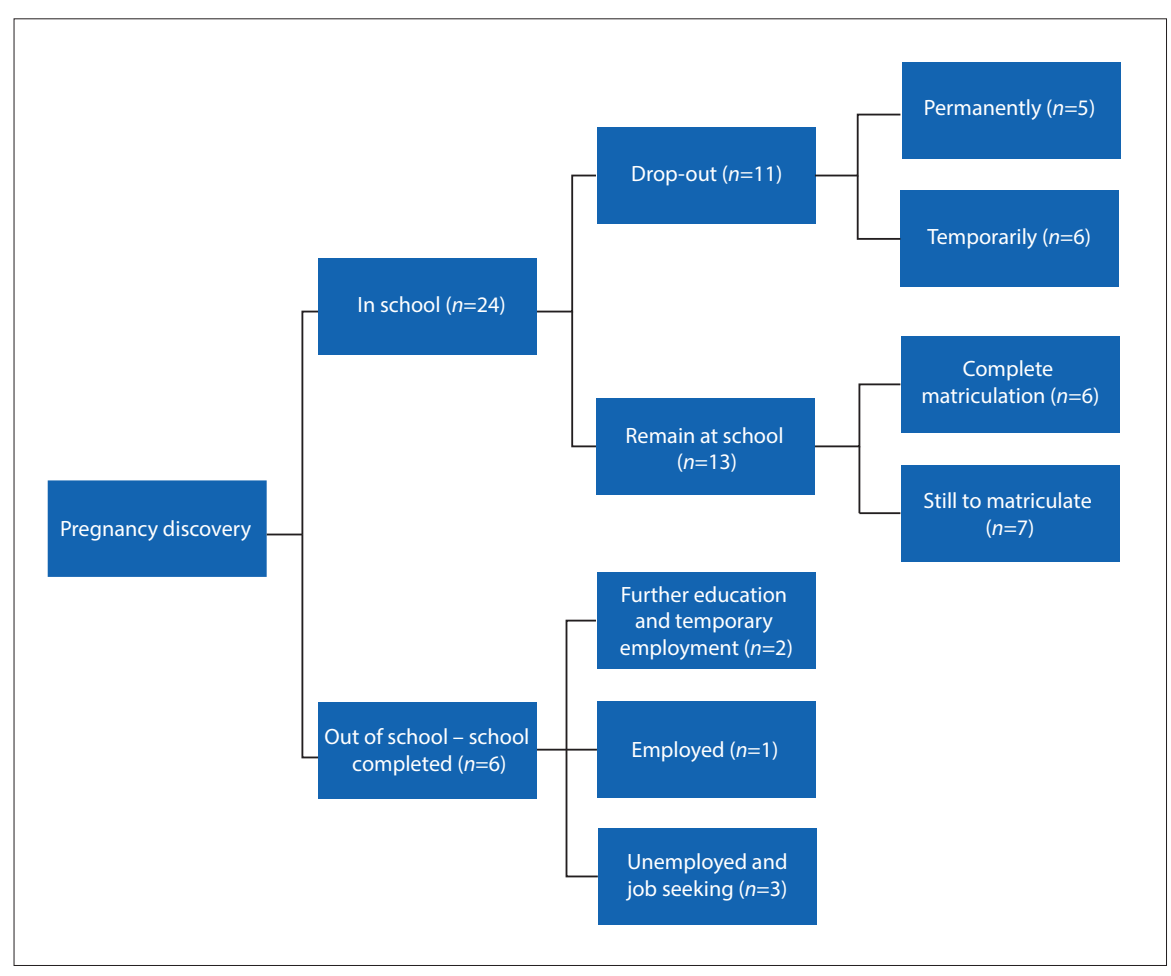

Fig. 1. Pathways to school completion after pregnancy. 
agency in advocating and creatively ensuring her daughter's right to be at school while pregnant. The grandmother who decided that her pregnant granddaughter should remain at home during the pregnancy exercised her agency and did what she believed would protect her grandchild from unnecessary danger and difficulty, so prioritising health and wellbeing over education. In this instance, the young pregnant woman had not been excluded by the school, and her temporary withdrawal related to perceptions of pregnancy health and wellbeing. The paternal grandmother who supported and cared for the young mother, illustrated her agency through her support, thereby fulfilling her family's and her sons' duty to mother and baby. Thus, the dominant idea of the absent and irresponsible father and his family is challenged. ${ }^{[22]}$ These cases illustrate the agency exercised by primary caregivers, who were all women, to support young mothers, reflecting the pervasive gendered nature of care.

The availability of crèches and opportunities for paid caregivers in the community enhanced women's chances of school completion. The child support grant allows young mothers to exercise agency in relation to the independent care and support of their babies, thereby increasing their opportunity to attend school. This is important in resource-poor urban areas where primary caregivers of mothers are the only employed members of households and so are unavailable for childcare. Use of the child support grant to pay for caregiving challenges the dominant idea of a perverse relationship between early childbearing and the grant - that the grant incentivises young motherhood, and is abused by young mothers for their social and personal needs ${ }^{[14,23,24]}$ Decisions by young mothers to seek private caregivers for their babies where there are overcrowded local crèches, further illustrates agency in caregiving decisions, and again disrupts perceptions of the irresponsible young mother. ${ }^{[14]}$

Aspiration for school completion and further education is high, but is tempered by challenges to matriculation completion, results, economic constraints, limited knowledge around further education and training, and early motherhood. Although young mothers articulated clear educational aspirations, they knew little about entry requirements, application procedures, and the associated costs and funding opportunities for further education. This behaviour mirrors national data that only $6.2 \%$ of South Africans under 24 attend postschool educational institutions. ${ }^{[25]}$

\section{Conclusion}

The present study illustrates that the pathway to school completion is complex and non-linear for some young mothers, affecting their education outcomes. The findings illustrate lower drop-out rates for young mothers than the national average, but further research is required to explore variations nationally, across rural and urban areas, and their relationship to a progressive policy environment and targeted campaigns that focus on improving educational outcomes for girls and young women. It illustrates the value of three particular interventions that policy addresses at a societal level and that benefit young mothers. These are the child support grant, the availability of crèches in the community, and school policy that upholds the principle of inclusivity for pregnant learners and young mothers.

Acknowledgements. The support of the DST-NRF Centre of Excellence in Human Development towards this research is hereby acknowledged. Opinions expressed and conclusions arrived at, are those of the author and are not necessarily to be attributed to the CoE in Human Development. The author gratefully acknowledges the support of the Demography and Population Studies Programme, Schools of Public Health and Social Sciences, Faculties of Health Sciences and Humanities, University of the Witwatersrand, Johannesburg, South Africa. The author gratefully acknowledges the contribution of all the young mothers who contributed to this study.

Author contribution. Sole author.

Funding. None.

Conflicts of interest. None.

1. Statistics South Africa (SSA). Education Series. Volume III: Education and Enrolment Achievement, 2016. Pretoria: SSA, 2017.

2. South African National Aids Council. South Africass National Strategic Plan for HIV, TB and STIs 2017-2022. http://sanac.org.za/wp-content/uploads/2017/05/ NSP_FullDocument_FINAL.pdf (accessed 18 December 2017).

3. Department of Education. Measures for the Prevention and Management of Learner Pregnancy. http://www.education.gov.za (accessed 18 December 2017).

4. Statistics South Africa (SSA). Census 2001: Stages in the life cycle of South Africans. Pretoria: SSA, 2005. http://www.statssa.gov.za/census/census_2001/ C2001_Stages/C2001Stages.pdf

5. South African Medical Research Council. South Africa Demographic and Health Survey, 2003: Full Report. Pretoria: Department of Health, MRC; 2007.

6. Statistics South Africa (SSA). South Africa Demographic and Health Survey, 2016: Key Indicator Report. Pretoria: SSA, 2017.

7. South African Medical Research Council. South Africa Demographic and Health Survey 1998: Full Report. Pretoria: Department of Health, MRC, 2002. http://www.mrc.ac.za/bod/SADHS1998FullReport.pdf (accessed 24 November 2017).

8. Panday S, Makiwane M, Ranchod C, Letsoalo T. Teenage pregnancy in South Africa: With a specific focus on school-going learners. Pretoria: Department of Basic Education, Human Sciences Research Council; 2009.

9. Ardington C, Branson N, Lam D, Leibbrandt M, Marteleto L. Revisiting the 'crisis' in teen births: What is the impact of teen births on young mothers and their children? Cape Town: University of Cape Town: Southern African Labour and Development Research Unit; 2011.

10. Hunter N, May J. Poverty, shocks and school disruption episodes among adolescents in South Africa. Durban: School of Development Studies, University of Natal; 2003.

11. Branson N, Hofmeyr C, Lam D. Progress through school and the determinants of school dropout in South Africa. Dev South Afr 2014;31(1):106-126. http:// www.tandfonline.com/doi/abs/10.1080/0376835X.2013.853610 (accessed 7 November 2017).

12. Shocking Drop-out Rates: Where in South Africa the fewest kids make it to matric. https://businesstech.co.za/news/general/149291/shocking-drop-outrates-where-in-south-africa-the-fewest-kids-make-it-to-matric/ (accessed 26 November 2017)

13. Bhana D, Mcambi SJ. When schoolgirls become mothers: Reflections from a selected group of teenage girls in Durban. Perspect Educ 2013;31(1):11-19.

14. Mkhwanazi N. A tough love approach indeed: Demonising early childbearing in the Zuma era. Agenda Empower Women Gend Equity 2012;26(4):73-84.

15. Mkhwanazi N. Revisiting the dynamics of early childbearing in South African townships. Cult Health Sex 2014;16(9):1084-1096. http://www.tandfonline. $\mathrm{com} / \mathrm{doi} / \mathrm{abs} / 10.1080 / 13691058.2014 .930512$ (accessed 31 October 2017).

16. Madhavan S, Thomas KJA. Childbearing and schooling: New evidence from South Africa. Comp Educ Rev 2005;49(4):452-467. http://www.jstor.org/ stable/10.1086/432770 (accessed 2 December 2017).

17. Marteleto L, Lam D, Ranchhod V. Sexual behavior, pregnancy, and schooling among young people in urban South Africa. Stud Fam Plann 2008;39(4):351368. http://0-onlinelibrary.wiley.com/doi/10.1111/j.1728-4465.2008.00180.x/ abstract (accessed 2 December 2017)

18. South African Schools Act No. 84 of 1996. 2011. https://www.gdeadmissions. gov.za/Content/Files/SchoolsAct.pdf (accessed 10 March 2018).

19. Bernard H. Research Methods in Anthropology: Qualitative and Quantitative Approaches. Oxford: Alta Mira Press; 2006

20. De Lanoy A, Swartz S, Lake L, Smith C. South African Child Gauge 2015. Cape Town: Children's Institute; 2015.

21. Chigona A, Chetty R. Girls' education in South Africa: Special consideration to teen mothers as learners. J Educ Int Dev 2007;3(1):1-17.

22. Richter LM, Morrell R, eds. Baba: Men and Fatherhood in South Africa. Cape Town: HSRC Press, 2006.

23. Monde M, Desmond C, Richter L, Udjo E. Is the Child Support Grant associated with an Increase in Teenage Fertility in South Africa? Pretoria: Human Sciences Research Council, 2016.

24. Patel L. Poverty, gender and social protection: Child support grants in Soweto, South Africa. J Policy Pract 2012;11(1/2):106-120. http://0-search.ebscohost. com.innopac. wits.ac.za/login.aspx? direct $=$ true \&db $=$ sih \&AN $=69838428 \&$ site $=$ ehost-live\&scope $=$ site (accessed 7 December 2017).

25. Statistics South Africa. Census 2011 Statistical Release. Pretoria: Statistics South Africa; 2012. https://www.statssa.gov.za/publications/P03014/P030142011.pdf (accessed 12 March 2018).

Accepted 27 March 2018 